
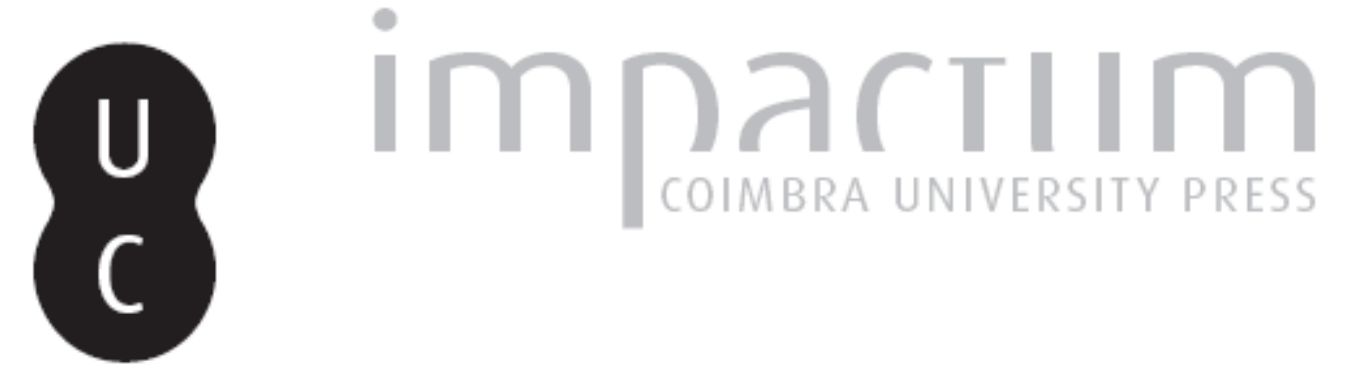

\title{
Conflito social e mecanismos para a sua resolução em primatas não-humanos: 0 caso dos macacos-uivadores
}

Autor(es): Garcia, Susana

Publicado por: CIAS - Centro de Investigação em Antropologia e Saúde

URL persistente:

URI:http://hdl.handle.net/10316.2/28613

DOI:

DOI:http://dx.doi.org/10.14195/2182-7982_28_6

Accessed : $\quad$ 26-Apr-2023 08:54:31

A navegação consulta e descarregamento dos títulos inseridos nas Bibliotecas Digitais UC Digitalis, UC Pombalina e UC Impactum, pressupõem a aceitação plena e sem reservas dos Termos e Condições de Uso destas Bibliotecas Digitais, disponíveis em https://digitalis.uc.pt/pt-pt/termos.

Conforme exposto nos referidos Termos e Condições de Uso, o descarregamento de títulos de acesso restrito requer uma licença válida de autorização devendo o utilizador aceder ao(s) documento(s) a partir de um endereço de IP da instituição detentora da supramencionada licença.

Ao utilizador é apenas permitido o descarregamento para uso pessoal, pelo que o emprego do(s) título(s) descarregado(s) para outro fim, designadamente comercial, carece de autorização do respetivo autor ou editor da obra.

Na medida em que todas as obras da UC Digitalis se encontram protegidas pelo Código do Direito de Autor e Direitos Conexos e demais legislação aplicável, toda a cópia, parcial ou total, deste documento, nos casos em que é legalmente admitida, deverá conter ou fazer-se acompanhar por este aviso.

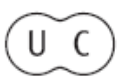




\section{Antropologia Portuguesa}

Departamento de Antropologia | Universidade de Coimbra

Volume $28 \cdot 2011$ 


\title{
Conflito social e mecanismos para a sua resolução em primatas não-humanos: o caso dos macacos-uivadores
}

\author{
Susana Garcia \\ Instituto Superior de Ciências Sociais e Políticas (UTL) \\ Centro de Administração e Políticas Públicas \\ msgarcia@iscsp.utl.pt
}

Resumo Este artigo descreve aspectos relacionados com o papel do conflito na organização social dos primatas não-humanos, com realce para as suas causas e formas. Mas, um estudo sobre conflito não ficaria completo sem focar também os mecanismos desenvolvidos por esta Ordem na minimização dos possíveis impactos negativos desse mesmo conflito. Assim, aborda-se também a importância do comportamento afiliativo e da reconciliação na dinâmica social dos grupos. Os pressupostos teóricos descritos ao longo do texto vão sendo exemplificados com dados comportamentais, recolhidos no âmbito de um projecto de investigação que visou o estudo do comportamento e organização social de um grupo de macacos-uivadores-de-manto no México.

Palavras-chave Conflito social; comportamento afiliativo; primatas não-humanos; macacos-uivadores.

Abstract This article aims to explore the role of social conflict on the social organization of non-human primates. The different causes and forms that the conflict may assume will also be described. A study about conflict would not be completed without looking at the mechanisms adopted by the primate order to minimize the possible negative impact of conflict itself. Thus, afiliative behavior and reconciliation will also be portrayed. The theoretical background presented throughout the text will be illustrated with behavioral data collected during a field study held on a group of Mexican howler monkeys.

Key words Social conflict; afiliative behavior; non-human primates; mantledhowler monkeys.

\section{Introdução}

A maioria dos primatas vive em grupos sociais coesos, embora a sociabilidade apresente, além de benefícios, custos. Os benefícios em viver num grupo grande, composto por várias fêmeas e vários machos adultos, são vários (Lee, 1994), mas apontam-se como principais a defesa conjunta 
de recursos (sobretudo pelas fêmeas) (Wrangham, 1979), a redução da vulnerabilidade face a predadores (van Schaik, 1983; 1996) e o controlo do infanticídio (van Schaik, 2000; Janson e van Schaik, 2000).

Em contrapartida, os conflitos internos tendem a aumentar em razão directa do aumento de elementos no grupo. As causas do conflito são inúmeras, mas, basicamente, podemos afirmar que dois indivíduos entram em conflito quando querem o mesmo recurso, ou, simplesmente quando os seus objectivos ou comportamento não são compatíveis. O conflito ocorre entre adultos e jovens, entre familiares e desconhecidos, ocorre entre machos e fêmeas e entre membros do mesmo sexo. Virtualmente, não existe nenhum contexto social onde o conflito ocasionalmente não surja (Mason, 1993).

A vida em grupos altamente estruturados, característica da maioria das espécies de primatas, não evoluiu através do desaparecimento das tendências competitivas e agressivas, mas através do desenvolvimento de mecanismos poderosos de resolução de conflitos (de Waal e van Roosmalen, 1979; de Waal, 1987; Kutsukake e Castles, 2001). A vida em grupo possibilita o estabelecimento de laços cooperativos de longa duração, daí que a regulação dos conflitos seja tão importante para os primatas e mamíferos sociais em geral.

Se nada em Biologia faz sentido se não for analisado à luz da evolução como já sustentava Dobzhanski em 1973, Darwin está presente em virtualmente todas as tentativas de se estudar e compreender o comportamento dos nossos parentes tão próximos - os primatas. Contudo, a leitura do comportamento social dos primatas não-humanos, mesmo tendo a obra On the origin of species by means of natural selection de Charles Darwin (1859) como inspiração, não tem sido fácil. Os primatas têm um ciclo de vida muito semelhante ao nosso (poucos descendentes e de maturação lenta) o que dificulta o teste dos pressupostos evolutivos.

Mesmo assim, neste artigo procura-se descrever algumas das forças que terão condicionado alguns comportamentos sociais dos primatas, com realce para o conflito e para a sua resolução. Neste percurso recorre-se a vários autores que têm reflectido sobre a evolução do comportamento dos primatas e também aos próprios macacos-uivadores, ou mais concretamente, à interpretação que fizemos do seu comportamento, para ilustrar as várias posições teóricas enunciadas. Os dados comportamentais que aqui se apresentam foram recolhidos junto a um grupo de macacos-uivadores-de-manto (Alouatta palliata mexicana), no México, durante seis meses (ver descrição do grupo, local e metodologia empregue em anexo). 


\section{Conflito de interesses: fundamentação teórica}

A Ecologia Comportamental postula que existem dois modos básicos de competição dentro dos grupos sociais. Quando os indivíduos não conseguem monopolizar os recursos alimentares devido a factores como a sua difícil detecção, grande dispersão geográfica, ou, inclusive, grande dimensão, embora estejam em competição, não lutam com frequência. Os indivíduos que consigam localizar e aproveitar melhor os recursos alimentares têm vantagens (scramble competition). Neste cenário, os indivíduos competem de forma indirecta e a escassez alimentar afecta todos, independentemente da sua posição social (van Hooff, 1992). Em contraste, se os recursos forem monopolizáveis, os indivíduos dominantes têm vantagens evidentes sobre os companheiros, estabelecendo-se no grupo uma hierarquia de dominância clara e baseada em alianças parentais (Janson, 2000). Neste último caso, a forma de competição já é direccionada, os vários indivíduos lutam uns contra os outros (contest competition).

Porém, a divisão acima referida não pode ser aplicada de forma universal, as relações sociais entre primatas são bastante complexas. Os indivíduos não lutam apenas por recursos alimentares, lutam também pelo acesso a parceiros sexuais, locais de descanso privilegiados, entre outros. A própria posição no grupo social pode espoletar conflitos. Os indivíduos dominantes podem ter vantagens menos evidentes, como por exemplo, um maior bem-estar psicológico e liberdade individual.

Trivers (1972) introduz a ideia de que machos e fêmeas estão limitados por factores diferentes. Enquanto os machos têm como principal prioridade garantir o seu acesso a parceiros sexuais, as fêmeas, ao investir muito mais nas crias (período de gestação e de lactação alargado) têm que se preocupar em garantir o acesso a recursos alimentares suficientes para si, e para a sua prole. Assim, a dispersão dos recursos influencia essencialmente as relações entre as fêmeas (Isbell, 1991; Koenig et al., 1998; Isbell e Young, 2002) e, por sua vez, a forma de competição entre as fêmeas influencia a organização social de todo o grupo. Machos e fêmeas têm interesses diferentes, e distintas motivações para competir, mas ambos os sexos competem entre si e com o sexo oposto.

Como a selecção natural actua ao nível dos indivíduos, favorecendo os que melhor maximizem as suas probabilidades de sobrevivência e de reprodução, o conflito é uma possibilidade não apenas quando estão em 
causa os recursos ou parceiros sexuais, mas também em relações que intuitivamente nos parecem menos prováveis de desencadear conflitos, por exemplo, entre grupos com um sistema de acasalamento monogâmico, irmãos, e entre progenitoras e crias. A selecção natural também favoreceu a evolução de estratégias para evitar, mitigar ou resolver os conflitos sociais, particularmente entre parentes próximos, animais mutuamente dependentes ou quando o risco de serem feridos é muito provável (Mason, 1993), mas também entre membros da mesma unidade social.

\section{Formas de competição}

Como a selecção da estratégia competitiva ideal está condicionada pelas estratégias desempenhadas pelos outros indivíduos do grupo, a teoria do jogo ajuda a compreender as interacções sociais conflituosas do ponto de vista evolutivo. Esta teoria procura interpretar as formas assumidas pelo conflito e explicar as soluções encontradas pelos indivíduos para a sua resolução.

A teoria evolutiva do jogo procura demonstrar o que sucederá se estratégias particulares forem jogadas contra elas próprias e contra outras alternativas, com o objectivo de medir os custos e os benefícios para os jogadores, em termos de sucesso reprodutivo (Garcia, 2001). A estratégia que ganhar contra ela própria e todas as outras num determinado campo de interacção é considerada uma estratégia evolutivamente estável [EEE (Maynard Smith, 1982)].

Uma EEE é definida como uma estratégia que, quando adoptada pela maioria dos indivíduos de uma população, tende a fixar-se, porque a selecção penalizará os seus desvios (Maynard Smith, 1993). No entanto, o comportamento é flexível e os primatas adaptam de forma dinâmica o seu comportamento ao dos outros indivíduos. Como foi demonstrado por Roberts e Sherratt (1998), em relação ao comportamento cooperativo, os indivíduos não 'dão tudo de uma vez', vão aumentando o investimento (raise the stake) à medida que a relação se torna mais forte e recíproca.

$\mathrm{Na}$ sua forma mais simples, a teoria do jogo considera que existem apenas em acção duas estratégias concorrentes: falcão ou pombo (Maynard Smith e Price, 1973; Maynard Smith, 1982). Os falcões lutam sempre o mais violentamente possível e nunca desistem da luta, mesmo que isso implique custos consideráveis (ex. ferimentos). Os pombos limitam-se a ameaçar de uma maneira convencional e evitam o contacto físico. 
Como Maynard Smith (1982) argumentou, nem uma nem outra estratégia é evolutivamente estável, porque poderia ser facilmente invadida pela outra estratégia concorrente, ou seja, numa população constituída só por pombos, os falcões teriam vantagens evidentes e vice-versa. Quando a população for constituída por indivíduos que alguma vez joguem como falcões, e outras como pombos, ou, em alternativa, por indivíduos que lutem sempre como falcões e outros sempre como pombos, atinge então o equilíbrio estável.

Os macacos-uivadores lutam sempre frente a frente, por isso as zonas lesionadas, em caso de luta, são preferencialmente a face, os braços, as mãos e o peito. Contudo, as lutas entre machos uivadores são muito raras. No nosso estudo incluímos apenas quatro categorias comportamentais que envolviam contacto físico (mordida, bofetada, empurrão e apertão), mas apenas foram observadas quatro ocorrências, no total. Neste contexto, podemos argumentar que os machos de Agaltepec procuravam evitar o contacto físico em contexto agonístico, comportando-se mais como pombos. Contudo, o macho alfa assumia uma postura mais próxima de um falcão do que os restantes indivíduos. A título ilustrativo, o macho alfa (Nico) do grupo de uivadores de Agaltepec sacudia e/ou partia ramos mesmo durante o período de descanso quando o grupo se encontrava imóvel (os macacos-uivadores descansam, deslocam-se e alimentam-se de forma sincronizada), sendo responsável por 42 por cento do total das emissões deste comportamento (Garcia, 2001). Este macho foi também o que emitiu o maior número de ameaças que tiveram como resposta um comportamento de submissão ou apaziguamento.

A teoria evolutiva do jogo analisa também quando é que o conflito ocorre e quais as suas causas. Esta corrente defende que os indivíduos antes de se envolverem numa situação conflituosa avaliam-se mutuamente e só entram em conflito se os benefícios superarem os custos. $\mathrm{O}$ agravamento do conflito torna-se mais provável quando os dois indivíduos têm mais ou menos o mesmo poder ou, em alternativa, quando não conseguem avaliar convenientemente as suas assimetrias (Maynard Smith e Parker, 1976). Tal como esperado, no grupo de macacos-uivadores-de-manto de Agaltepec, os conflitos surgiam maioritariamente entre indivíduos que ocupavam posições próximas na hierarquia de dominância (Garcia, 2001).

A teoria dos jogos explica, com bastante sucesso, o resultado do encontro entre animais que não vivem em grupo (ex. insectos, aranhas, peixes, etc.), 
contudo, esta corrente poderá ser insuficiente para explicar a diversidade comportamental da Ordem dos Primatas (Matsumura e Okamoto, 2000). Franz de Waal (1996) propôs um novo paradigma para explicar como é que os primatas resolvem os seus conflitos de interesse (Figura 1).

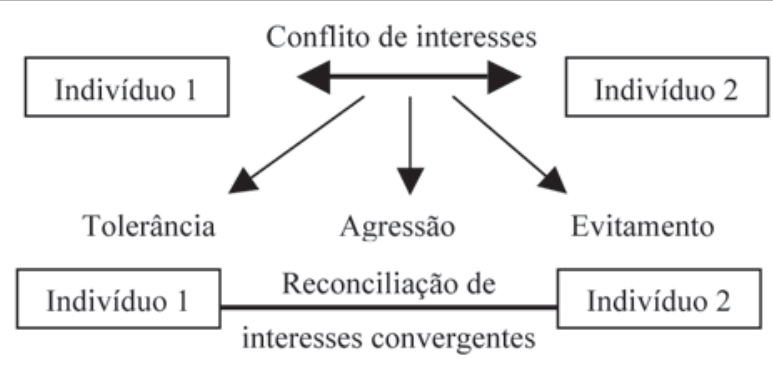

Figura 1. Modelo relacional (adaptado de de Waal, 1996).

Neste modelo teórico, o comportamento agressivo é apenas uma das muitas formas de resolver os conflitos. Os indivíduos podem optar também pela tolerância (ex. partilha de recursos) ou por evitarem o confronto. Se optarem pela agressão, a natureza da relação determina se os indivíduos se vão tentar reconciliar ou não. Se os indivíduos tiverem interesse em manter a relação, reconciliam-se. Assim, os indivíduos ajustam os termos da sua relação através de ciclos de conflito e de reconciliação (de Waal, 1996).

Com esta mudança de perspectiva a definição do que é uma relação próxima ou distante alterou-se drasticamente. Em vez de se classificarem as relações tendo apenas como base as taxas de comportamento afiliativo ou agressivo, começou-se a dar mais relevância à dinâmica gerada entre estes dois conjuntos de comportamento. As relações marcadas por altas taxas de agressão podem inclusive ser mais fortes e cooperativas (de Waal, 2000). Algumas espécies de primatas, como é o caso de espécies pertencentes ao género Macaca, desenvolvem relações de parentesco muito fortes e complexas, mas os comportamentos agressivos mais violentos também ocorrem dentro da linhagem parental (Bernstein e Ehardt, 1986). Segundo Cords e Aureli (2000) este aparente paradoxo é possível devido à grande tendência conciliatória que caracteriza as relações importantes.

Desde sempre que se associou conflito social e agressividade, mas hoje sabemos que o conflito não é sinónimo de agressão. A maioria dos conflitos nem sequer envolve qualquer tipo de comportamento agressivo, a 
agressão é apenas um aspecto do conflito. As formas que o conflito assume podem ser muito subtis e ritualizadas (Walters e Seyfarth, 1987; Sousa e Casanova, 2005/2006).

Na tabela 1 foram incluídos os comportamentos agonísticos (mordida, empurrão, ameaça, partir e/ou sacudir ramos e perseguição) que tiveram como resposta um comportamento submisso (apaziguamento e fuga) e foram excluídas as sequências de aproximação-afastamento que são apresentadas na tabela 2. Como se pode observar nas tabelas 1 e 2 o único padrão comportamental comum no grupo de Agaltepec foi o denominado por Rowell (1966) por aproximação-afastamento (approach-retreat). Como a expressão sugere, um indivíduo aproxima-se de outro sem esboçar qualquer sinal de ameaça e o outro afasta-se, abandonando o local de descanso ou de alimentação que ocupava. Este padrão comportamental foi importante na análise da dinâmica competitiva do grupo de Agaltepec. Para além de ser muito comum, foi observado em todos os contextos considerados.

Tabela 1. Comportamentos agonísticos que tiveram como resposta um comportamento submisso.

\begin{tabular}{|c|c|c|c|c|c|c|c|c|c|c|c|c|c|c|}
\hline & & \multicolumn{13}{|c|}{ Receptor } \\
\hline & & $\mathrm{NC}$ & PC & NK & SB & $\mathrm{CH}$ & CR & RO & PR & VE & SN & PN & $\mathrm{NF}$ & $\mathrm{T}$ \\
\hline \multirow{13}{*}{ 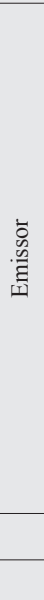 } & $\mathrm{NC}$ & - & 7 & 2 & & & 2 & 1 & 5 & 5 & & 1 & & 23 \\
\hline & $\mathrm{PC}$ & 2 & - & & & 6 & 2 & & 2 & 1 & & 1 & 1 & 15 \\
\hline & NK & & & - & & 2 & 4 & & & & & & 2 & 8 \\
\hline & $\mathrm{SB}$ & & & & - & & 2 & 1 & & & 1 & 1 & & 5 \\
\hline & $\mathrm{CH}$ & 2 & & 1 & & - & & & 1 & & & & & 4 \\
\hline & CR & 2 & & & & & - & & & & 1 & 1 & & 4 \\
\hline & RO & & & & 2 & & & - & & & & & & 2 \\
\hline & PR & & & & 1 & & 1 & & - & & & & & 2 \\
\hline & VE & & & & & & & & 1 & - & & & & 1 \\
\hline & SN & & & & & & & & & & - & & & - \\
\hline & PN & & & & & & & & & & & - & & - \\
\hline & $\mathrm{NF}$ & & & & & & & & & & & & - & - \\
\hline & $\mathrm{T}$ & 6 & 7 & 3 & 3 & 8 & 11 & 2 & 9 & 6 & 2 & 4 & 3 & 64 \\
\hline
\end{tabular}


Tabela 2. Sequências de aproximação-afastamento.

\begin{tabular}{|c|c|c|c|c|c|c|c|c|c|c|c|c|c|c|}
\hline & & \multicolumn{13}{|c|}{ Receptor } \\
\hline & & $\mathrm{NC}$ & PC & NK & SB & $\mathrm{CH}$ & CR & $\mathrm{RO}$ & PR & VE & SN & PN & $\mathrm{NF}$ & $\mathrm{T}$ \\
\hline \multirow{13}{*}{ 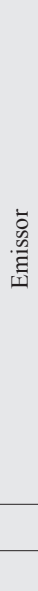 } & $\mathrm{NC}$ & - & 7 & 2 & 7 & 3 & 3 & 1 & 2 & 1 & 5 & 1 & 3 & 41 \\
\hline & PC & 1 & - & & 1 & 6 & 3 & & 2 & 4 & 7 & 6 & 7 & 37 \\
\hline & NK & 1 & 2 & - & 1 & 1 & 1 & & 1 & 4 & 14 & 4 & 5 & 34 \\
\hline & SB & & 9 & & - & 4 & 1 & 1 & 4 & 2 & 6 & 1 & 4 & 32 \\
\hline & $\mathrm{CH}$ & 4 & & 3 & 1 & - & 1 & 1 & 3 & 2 & 2 & 5 & 2 & 24 \\
\hline & CR & 1 & & 2 & & 3 & - & 1 & 3 & 1 & 4 & 5 & 3 & 23 \\
\hline & RO & & 1 & & 5 & 4 & 2 & - & 1 & 3 & 1 & & 31 & 21 \\
\hline & PR & & 1 & & 1 & 3 & 4 & 2 & - & 1 & 4 & 2 & 2 & 20 \\
\hline & VE & & & 2 & & & & 1 & & - & 2 & 1 & & 6 \\
\hline & $\mathrm{SN}$ & & & & & & & 2 & & & - & 2 & & 4 \\
\hline & PN & & & & & & & & & 1 & & - & & 1 \\
\hline & NF & & & & & & & & & & & & - & - \\
\hline & $\mathrm{T}$ & 7 & 20 & 14 & 16 & 24 & 15 & 9 & 16 & 19 & 45 & 31 & 27 & 243 \\
\hline
\end{tabular}

Os machos de Agaltepec envolvem-se em conflito em contextos específicos, tais como: alimentação $(n=104)$, fêmeas sexualmente receptivas $(n=34)$ e suplante de local ( $n=23)$. A manutenção da distância interindividual também motiva várias aproximações-afastamentos $(n=108)$, mas como não visa a obtenção de algo específico, alguns autores classificam estas interacções como sem contexto (Lee, 1983).

Os primeiros primatólogos a realizar trabalho de campo com esta espécie descreveram os machos como extremamente tolerantes, mesmo no contexto sexual (Carpenter, 1965), todavia, estudos posteriores vieram colocar esta ideia em causa (Clarke, 1981; 1984; Jones, 1985). Em Agaltepec, os machos procuravam assegurar o seu acesso a fêmeas sexualmente receptivas, e, de facto, o estatuto hierárquico correlaciona-se de forma positiva com o número de cópulas $\left(r^{s}=0,731, p<0,01\right)$ e de consórcios $\left(r^{s}=0,808, p=0,001\right)$ que cada macho conseguiu. Por consórcio entende-se um comportamento também denominado como guarda do par, no qual se forma uma coligação entre um macho e uma fêmea sexualmente receptiva, podendo acontecer dentro ou fora do grupo. O consórcio era uma estratégia reprodutiva dos indivíduos dominantes, tendo apenas um macho (Cristóbal) de estatuto hierárquico mais baixo conseguido manter uma situação de consórcio fora do grupo. Esta realidade talvez possa ser explicada pela incapacidade dos subordina- 
dos em conseguirem guardar as fêmeas na presença de outros machos com um estatuto social mais elevado (Garcia, 2001). Mesmo assim, a maioria das cópulas ocorreu no contexto do grupo. Durante o período de recolha de dados apenas dois machos não copularam e outros dois copularam de forma oportunista, ou seja, antes da cópula acontecer olharam de forma ostensiva em seu redor, provavelmente para se certificarem de que não se encontravam outros machos na proximidade, e só depois copularam muito rapidamente.

A agressividade também faz parte do repertório comportamental dos uivadores, apesar de só ocorrer muito esporadicamente. Os machos podem agredir-se com violência, provocando cicatrizes permanentes na face, membros e cauda. Durante o período de recolha de dados apenas se observou um macho a dar uma mordida a outro, mas, neste período, um macho ficou gravemente ferido no lábio (observação ad libitum). Este macho, devido ao confronto, ficou com o lábio inferior rasgado, de forma permanente, o que dificultava a sua alimentação.

\section{A formação de hierarquias de dominância e o controlo da agressividade}

O resultado mais evidente do conflito consiste na formação de hierarquias de dominância: os indivíduos ao competirem uns contra os outros vão estabelecendo relações de dominância e de submissão complexas, e, essa teia de relações é denominada por hierarquia social de dominância (HSD). A HSD pode funcionar como um mecanismo controlador da agressividade, na medida em que aumenta a previsibilidade das atitudes dos outros indivíduos do grupo (Casanova, 1996). Em princípio, se a hierarquia de dominância for estável, as relações entre os indivíduos normalizam e os comportamentos agressivos diminuem.

Segundo Preuschoft e van Schaik (2000), as hierarquias tendem a ser estáveis devido a três aspectos. Em primeiro lugar, os dominantes ao terem determinados benefícios, como acesso privilegiado a recursos, reforçam a sua posição. Se as diferenças de estatuto forem consideráveis, os dominantes, à partida melhor alimentados, são mais fortes e tendem a ter mais descendentes (possíveis aliados). Em segundo lugar, os animais tentam manter o estatuto adquirido, gerindo os conflitos no grupo de modo a não ocorrerem alterações que possam ameaçar a sua posição. Por último, os autores consideram a formação de alianças ao nível das matrilíneas. Em 
algumas espécies (ex. macacos-japoneses, Macaca fuscata), a hierarquia pode manter-se inalterável durante anos, por exemplo, num grupo estudado por Takahata (1991 in Preuschoft e van Schaik, 2000), a hierarquia só mudou duas vezes em doze anos.

Convém aqui realçar que o comportamento de subordinação também é aprendido. Nos primeiros encontros entre dois indivíduos, dá-se uma medição de forças, mas com a acumulação de encontros o tempo despendido nesta avaliação mútua vai decaindo. Os indivíduos estabelecem uma relação de dominância-subordinação em que o habitual vencido evita o vencedor à mera aproximação deste. $\mathrm{O}$ habitual vencido, mesmo que se torne mais robusto, tende a não desafiar o dominante. Por vezes, quando esta relação hierárquica está bem definida, os indivíduos podem, simplesmente, deixar de interagir (de Vries et al., 2006).

Wilson (1975) defende que a formação de hierarquias de dominância faz com que a competição entre membros de um grupo social por recursos escassos diminua, embora esta afirmação possa não ser aplicável aos grupos de primatas não-humanos. O grupo de Agaltepec é demograficamente instável, devido ao aumento exponencial da população da ilha e à entrada constante de machos periféricos que têm que definir a sua posição. Os machos quando atingem a puberdade vivem durante largos meses isolados do grupo e raramente são vistos pelos observadores. Acabam por ser integrados no grupo devido à impossibilidade física de emigrarem para outra unidade social. A hierarquia social é dinâmica conduzindo a níveis de comportamento agonístico relativamente elevados $(0,53 /$ hora $)$ se considerarmos que os uivadores apenas gastam 0,35 por cento do seu tempo em interacções sociais (Richard, 1970). Os machos têm necessidade de continuar a exibir as suas capacidades para se manterem como dominantes: altas taxas de agonísmo parecem ser uma condição necessária para os dominantes manterem o seu estatuto num ambiente social em mudança (Bernstein, 1981). Assim, neste grupo, registaram-se 307 interacções agonísticas em que se pôde identificar um vencedor e um vencido. Este valor é elevado se considerarmos que os uivadores (principalmente os machos adultos) não se relacionam socialmente com frequência em habitat natural. Aliás, a pouca interacção social não é uma exclusividade dos macacos-uivadores. No trabalho de síntese elaborado por Sussman et al. (2005) conclui-se que os primatas que vivem em habitat natural dedicam menos de 10 por cento do seu tempo disponível a interacções sociais activas. No caso dos uivadores este valor ainda é mais reduzido (Milton, 1980). 
Os autores Robert Boyd e Joan Silk (1983) escreveram que as relações de dominância são geralmente caracterizadas por três propriedades estruturais: estabilidade, transitividade e linearidade. Esta definição clássica de dominância não se aplica ao nosso grupo, e provavelmente, não se aplica a muitos outros grupos e espécies de primatas não-humanos. Neste grupo, as relações parecem ser instáveis e não são transitivas nem lineares, apesar de se notar uma certa tendência para a linearidade patente no valor obtido no Índice de Landau e que foi de 0,8 .

A dominância é um fenómeno dinâmico e mais complexo do que se pensava. Enquanto hierarquias estáveis, de longa duração, caracterizam muitas espécies de primatas, noutras espécies, as hierarquias de dominância são instáveis, confusas, ambíguas, ou aparentemente não existentes (Walters e Seyfarth, 1987).

Possivelmente, a maioria dos indivíduos deste grupo possui capacidades competitivas similares, pelo que a hierarquia reflecte um sistema de classes. Quando a hierarquia é linear, temos $\mathrm{A}>\mathrm{B}>\mathrm{C}$ então $\mathrm{A}>\mathrm{C}$, num sistema de classes as relações hierárquicas são mais complexas e a formação das classes muda consoante os grupos, como exemplo temos: $([\mathrm{A}+\mathrm{B}]>[\mathrm{C}=\mathrm{D}+\mathrm{E}+\mathrm{F}])$. No grupo analisado, identificaram-se quatro classes principais, que podem ser visualizadas através da análise de Cluster (Figura 2). As matrizes também foram analisadas com o método de delimitação de posições cardinais desenvolvido por Boyd e Silk (1983), e obtiveram-se resultados similares (Garcia, 2001).

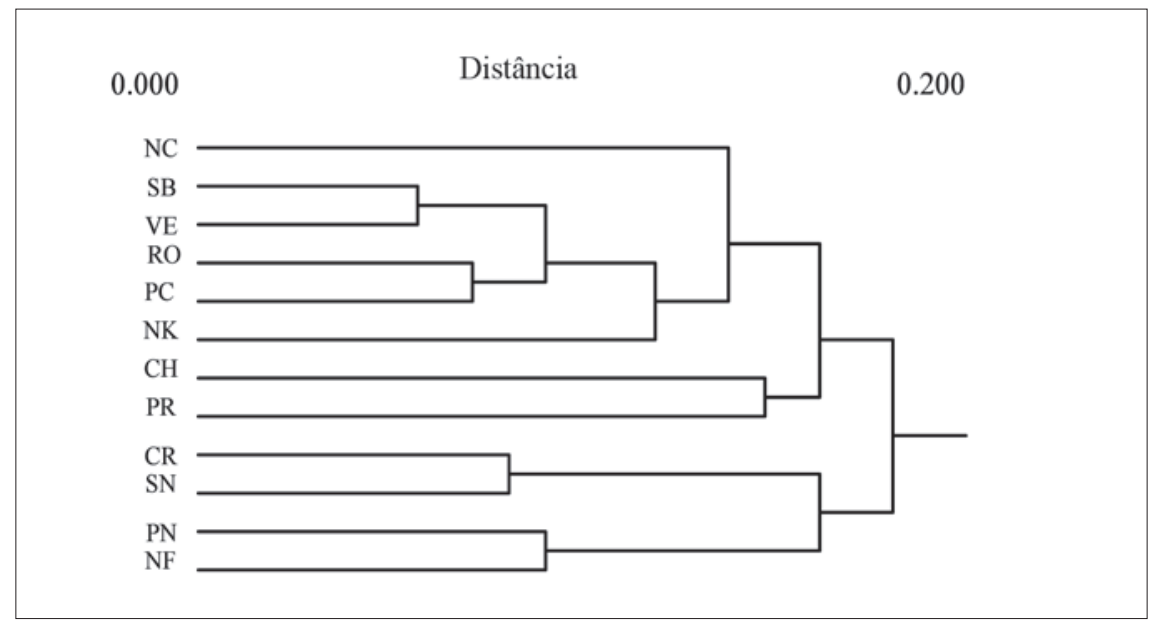

Figura 2. Análise de cluster. 
Segundo van Hooff e van Schaik (1992), sempre que seja impossível ou muito difícil restringir o acesso de outros indivíduos aos recursos, a dominância não aumentará o sucesso reprodutivo dos dominantes, portanto, as relações de dominância deverão ser fluidas e instáveis e as coligações deverão ser raras. Neste caso, é possível que o elevado número de machos residentes no grupo explique a falta de linearidade e não tanto a impossibilidade de controlo de recursos, pois em grupos pequenos, constituídos por um a quatro machos adultos, os machos uivadores formam entre si uma hierarquia linear (Zucker e Clarke, 1998). Em termos biológicos, não existe nenhum imperativo para que as hierarquias sejam lineares. Como a hierarquia é formada, em primeira análise, pelos confrontos em díade de todos os membros do grupo, então só faz sentido haver uma hierarquia linear se as diferenças na capacidade para manter recursos forem bastante assimétricas.

Em certos grupos, a hierarquia estabelecida num determinado contexto não é coincidente com a hierarquia estabelecida num outro, o que levou alguns autores a duvidar da aplicabilidade do conceito de dominância. Esta situação ocorre porque a dominância não é uma propriedade intrínseca aos indivíduos, como Slater (1986) argumentou, mas é o resultado de uma relação, daí que as ordens hierárquicas variem consoante os contextos analisados (Fedigan, 1992). Neste grupo, as ordens hierárquicas encontradas consoante os vários contextos (alimentar, sexual, distância social, suplante de local), correlacionam-se de forma positiva, pelo que podemos concluir que as posições hierárquicas de cada indivíduo são consistentes independentemente do contexto seleccionado (Garcia, 2001).

Alguns autores consideram que se dá demasiada importância aos estudos de dominância social (Casanova, 1996). E, Bernstein (1981) defende inclusive que as hierarquias de dominância são apenas arbitrariedades fruto da capacidade humana para categorizar. Mas, como refere de Waal (1989a), uma vez que as relações de dominância são avaliadas e reconhecidas pelos próprios animais, então não podem ser consideradas como meras abstracções efectuadas pelo observador. Os primatas procuram, claramente, estabelecer dominância sobre outros e formalizam as assimetrias resultantes através de comunicação ritualizada (de Waal, 1989a). De facto, a formação de hierarquias de dominância estáveis pode diminuir os conflitos dentro do grupo. de Waal estudou durante décadas uma comunidade de chimpanzés no Jardim Zoológico de Arnhem (Holanda) e observou que nos anos em que a hierarquia de dominância era instável havia cinco vezes mais lutas (de Waal, 1982). 
No grupo de Agaltepec tornou-se evidente que o facto de os indivíduos reconhecerem outros como dominantes também evitou alguns conflitos, uma vez que os mais subordinados simplesmente diferiam para os mais dominantes. Os próprios macacos, tal como os seus observadores humanos, ordenam os membros do seu grupo, ou seja, constroem uma hierarquia para além da simples categorização: dominante em relação a mim e subordinado em relação a mim. Tal como Seyfarth (1981) observou em macacos-verdes (Chlorocebus aethiops), os macacos neste grupo, agem de maneira diferenciada em relação a indivíduos que ocupam uma posição na hierarquia muito distante e indivíduos que ocupam uma posição pouco distante. O conflito ocorria com alguma frequência entre indivíduos com uma posição próxima na hierarquia, como se os indivíduos continuassem a medir forças entre si. $\mathrm{E}$, como se referiu, era raro entre indivíduos dos extremos da hierarquia (Garcia, 2001).

A dominância pode trazer benefícios tangíveis, mas será que os indivíduos procuram atingir um estatuto elevado per se? Os vários machos, consoante a sua posição na hierarquia apresentam perfis comportamentais diferenciados, e, algumas estratégias são melhor sucedidas que outras, mas as motivações que levam alguns indivíduos a desempenhar determinadas acções e não outras ainda são estranhas aos investigadores. Apesar de o macho alfa apresentar uma estratégia diferenciada e eficaz, não sabemos se este macho se comportava desta forma para assegurar a sua posição hierárquica no grupo.

Segundo Mason (1993), não há provas de que os animais lutem com o objectivo último de atingirem um estatuto elevado. Na opinião do autor, os primatas envolvem-se em conflito para optimizarem a sua liberdade e mobilidade individual em circunstâncias exigentes, ou seja, competem por incentivos desejáveis mútuos. Por outras palavras, o indivíduo pode não ter como objectivo último subir na hierarquia, mas sim maximizar o seu bemestar, minimizando contrariedades e frustrações.

Independentemente das suas motivações, alguns machos conseguiram competir com mais sucesso em vários contextos, como o alimentar e o sexual. Desconhece-se porém, se este aparente sucesso se traduziu em vantagens reprodutivas. Teoricamente, espera-se que os dominantes tenham sucesso reprodutivo, pois conseguem monopolizar as fêmeas em estro com mais eficiência (Cowlishaw e Dunbar, 1991). Contudo, tal como acontece noutras espécies de primatas com uma estrutura social multimacho/multifê- 
mea, o papel da competição espermática pode ser determinante no sucesso reprodutivo de cada macho (Harcourt et al., 1981; 1995). Nestes casos, é possível que o número de cópulas não seja um indicador fiável do sucesso reprodutivo de cada macho.

Em suma, a dominância diádica pode ser considerada como uma convenção, constituída por um conjunto de regras que dizem aos animais quando devem insistir no conflito, ou mesmo agravá-lo, e quando devem protelar. Neste sentido, a hierarquia de dominância contribui para a diminuição da agressividade nos grupos de primatas.

\section{Resolução de conflitos e o papel dos comportamentos afiliativos}

Tradicionalmente, a teoria evolutiva dava muita importância aos comportamentos agressivos, considerava que os indivíduos tinham interesses incompatíveis, com a consequente sobrevivência do mais apto. A possibilidade de que os indivíduos pudessem partilhar interesses era tão remota que quando se procurou explicar a raridade da violência letal, em vez de se assumir que os indivíduos tinham necessidade de cooperar, as explicações se centraram exclusivamente nos riscos físicos do combate (Maynard Smith e Price, 1973; Sussman et al., 2005).

de Waal (1996) critica largamente esta perspectiva por assumir que os indivíduos não estão rodeados de amigos e família mas sim de rivais. Os indivíduos só tinham duas opções: ou ganhavam os conflitos ou eram derrotados, não sendo necessário haver reconciliação, contudo, as opções dos indivíduos podem ser bem mais complexas. Os indivíduos antes de competirem consideram não apenas o valor do recurso, ou o risco físico na sua obtenção, mas também o valor da relação (de Waal, 1989b).

Na opinião de de Waal (1989a), tanto os primatas não-humanos como humanos sabem que nem sempre podem ganhar uma luta sem perder um amigo, por isso, o comportamento conciliatório é fundamental para a manutenção pacífica das relações entre os primatas (de Waal, 1996) e mamíferos sociais em geral. Além disso, como os primatas têm uma esperança média de vida muito elevada e vivem a maior parte da sua vida no mesmo grupo, investem em relações sociais estáveis e duradouras. Logicamente, não querem desperdiçar esse investimento e quando brigam procuram reconciliar-se. Neste sentido, Aureli e de Waal (2000) definem o termo reconciliação do seguinte modo: encontro amigável que ocorre entre dois rivais, logo após 
estes se terem envolvido em conflito, que tem como objectivo restaurar as suas relações sociais. Em síntese, a reconciliação é um mecanismo de resolução de conflitos.

Joan Silk propõe, em várias publicações (ex. 1996; 1997; 2000), uma explicação alternativa para a ocorrência habitual de interacções afiliativas após um conflito. Silk defende que estes comportamentos são sinais honestos que indicam aos indivíduos rivais que o conflito terminou, pois a incerteza pode ser muito desgastante. Estes contactos afiliativos evitam que os adversários tenham receio de se aproximarem uns dos outros e de retomarem os contactos pacíficos. Silk e colaboradores (1996) afirmam também que não há provas concretas que indiquem que a reconciliação preserve as relações sociais a longo prazo, nem de que este comportamento seja necessário para a manutenção da coesão do grupo. As duas definições coincidem na visão de que estes encontros amigáveis, ao ocorrerem quase imediatamente após o conflito, ajudam a acalmar os participantes, mas se a reconciliação tem apenas um fim imediato, como Silk postula, ou se tem uma função que se prolonga no tempo, ainda é motivo de discussão (van Hooff, 2001).

Os macacos-uivadores têm sido considerados como pouco afiliativos e de 'não-contacto', no entanto o comportamento afiliativo parece desempenhar, neste grupo, um papel importante enquanto regulador da vida social. Os principais comportamentos afiliativos observados foram a cerimónia de saudação (greeting ceremony) e o jogo de luta (play fighting). Curiosamente, ambos os comportamentos envolvem contacto físico e apresentaram no nosso estudo uma incidência muito alta $(n=165)$, tendo em consideração outros estudos realizados com esta espécie e, sobretudo, porque apenas se estudaram machos adultos. Asensio (2003) realizou um estudou comparativo também na região de Veracruz e verificou que os machos de Agaltepec interagem mais do que os machos dos restantes grupos. Esta elevada ocorrência pode ser explicada, precisamente, pelo elevado número de machos presentes no grupo (Kappeler e van Schaik, 2002).

A cerimónia de saudação $(n=106)$ era desempenhada de forma espontânea (sem qualquer razão identificada) ou então dentro de dois contextos: quando os indivíduos se cruzavam num dado ramo ou quando um macho chegava a um subgrupo. Como o grupo de macacos-uivadores-de-manto de Agaltepec era constituído por mais de 50 indivíduos, enquanto em habitat natural a dimensão típica dos grupos oscila entre os 6 e os 23 indivíduos (Crockett e Eisenberg, 1987), os animais dividiam-se, temporariamente, em 
subgrupos. Esta estratégia pode ter-lhes permitido usar os recursos de forma mais eficiente e também pode ter tido como consequência a diminuição dos confrontos. A coexistência permanente de doze machos adultos pode ter aumentado o potencial agressivo no grupo. Assim, o macho recém-chegado ao ir saudar o macho mais próximo diminuía a tensão latente entre os dois e evitava a sua escalada para níveis difíceis de gerir. $\mathrm{O}$ indivíduo que saudava mostrava claramente ao outro as suas intenções afiliativas.

Como notam Colmenares et al. (2000) a cerimónia de saudação tem como função reduzir as tendências agonísticas (medo ou agressão), essencialmente porque reduz a incerteza quanto ao comportamento do outro. As saudações assinalam a intenção não agonística do emissor, provocam uma resposta não agonística por parte do receptor e facilitam a ocorrência de interacções afiliativas, especialmente, se a relação entre os dois indivíduos já fosse um pouco tensa.

Depois da saudação, os machos afastavam-se e retomavam a sua actividade normal. Em algumas situações (20,7\%), os machos saudaram-se após uma sequência de aproximação-afastamento, mas na grande maioria das interacções agonísticas (79,3\%), os machos procuraram afastar-se rapidamente, não se observando qualquer interacção afiliativa pós-conflito. De facto, após o abraço, os indivíduos pareciam mais tranquilos, mas não parece provável que o fim último da saudação fosse a reconciliação, pois raramente ocorreu após um conflito. Na nossa opinião, os machos desempenharam este comportamento simplesmente para diminuir a tensão entre eles e não tanto para preservar a relação. Neste sentido, a explicação de Silk (1996) aplica-se melhor aos macacos-uivadores.

Em relação ao jogo de luta $(n=59)$, a sua ocorrência em habitat natural é ainda mais rara (Fontaine, 1994; Asensio, 2003), e, tal como a cerimónia de saudação, o jogo de luta ocorre com regularidade em Agaltepec, o que também pode fomentar a coesão social do grupo. Pellis e Pellis (1996) sugerem que a função principal deste tipo de jogo após a puberdade é a manipulação social, tanto no recrutamento e manutenção de amizades como no melhoramento do estatuto individual. $\mathrm{O}$ jogo permite que os vários machos se testem mutuamente, pois o indivíduo ao jogar explora as suas possibilidades em relação aos outros membros do grupo.

Em Agaltepec, o jogo poderia desempenhar uma dupla função. Se, por um lado, permitia que os indivíduos medissem forças, por outro, parece inegável que o comportamento afiliativo, através de contacto físico ocasional, 
contribuiu de forma significativa para a diminuição da tensão entre os vários machos. O simples toque é muito importante como mecanismo regulador da tensão social entre dois indivíduos humanos ou não-humanos. Não será por acaso que a maioria dos grupos humanos pratique formas de saudação que envolvem contacto físico.

Apesar de o termo reconciliação ter sido proposto por de Waal e van Roosmalen em 1979, só na última década é que se começou realmente a dar importância ao comportamento afiliativo. Um dos primatólogos que mais tem defendido a importância destes comportamentos tem sido Robert Sussman. O autor e colaboradores (2005) criticam o peso que os primatólogos atribuem ao comportamento agressivo, argumentando que os comportamentos afiliativos são muito mais comuns do que os de natureza agonística e são executados durante muito mais tempo. Defende mesmo que os comportamentos afiliativos constituem as principais forças modeladoras da sociabilidade entre os primatas.

Mas Sussman não está sozinho, nos últimos anos inúmeros estudos teóricos sobre cooperação têm sido publicados em revistas científicas de elevado factor de impacto (ex. Nature) e Kappeler e van Schaik (2002) defendem mesmo que é a única temática, dentro da biologia evolutiva, em que há uma forte representação dos estudos em Primatologia. A importância atribuída aos comportamentos afiliativos, e em especial à cooperação, tem crescido ao longo do tempo. Recentemente, Roberts (2005) propôs que os indivíduos cooperam porque a vida em grupo gera uma dinâmica de interdependências que promove a cooperação entre os vários elementos, mesmo que os benefícios não sejam imediatos. Cooperar é uma estratégia evolutivamente estável, porque independentemente da resposta dos outros, compensa sempre. Esta posição dá ainda mais relevo à cooperação do que publicações prévias do mesmo autor (Roberts e Sherratt, 1998).

Esta mudança de perspectiva foi também acompanhada de forma paralela pelas outras áreas científicas, como é o caso do Direito. Tradicionalmente, a lei era usada para controlar a agressão através da ameaça ou mesmo do uso da força, a lei estava desenhada para terminar o conflito e não para o resolver (Yarn, 2000). Hoje em dia, entendem-se os advogados como agentes mediadores de conflitos, sendo o ideal conciliar as partes envolvidas e não puni-las (Yarn, 2000).

No caso da espécie Alouatta palliata mexicana, mesmo que as interacções afiliativas observadas, em especial a cerimónia de saudação, sirvam 
para assegurar que as relações entre os machos continuam não agressivas, tal como foi notado por Strier (1992) em muriquis (Brachyteles arachnoides), não deixam de desempenhar um papel muito importante na dinâmica social do grupo.

\section{Considerações finais}

Nos anos 60 e 70 os etólogos assumiam que a agressão era algo latente nos indivíduos, ou seja, os indivíduos eram agressivos por natureza e essa agressão era muito difícil de controlar, surgindo assim o desporto nas sociedades humanas como forma de substituição ou escape a essa agressão inata (Lorenz, 1992). Posteriormente, começou-se a considerar a agressão como o produto do conflito de interesses e não um estado interno, e, no presente, a agressão é entendida apenas como uma das possíveis formas de resolução de conflitos. A nova perspectiva vê a agressão como um instrumento de negociação entre indivíduos; o conflito e a competição podem ser considerados apenas como mais um dos elementos que formam a estrutura e a organização social dos grupos de primatas, desempenhando em algumas circunstâncias um papel vital na manutenção da vida em grupo.

Embora as relações agonísticas entre primatas se resumam, na maioria das vezes, a simples ritualizações representativas do estatuto social de cada indivíduo, a agressividade esporádica pode ser necessária para definir compromissos e terminar uma situação tensa. Sem a ocorrência destes encontros agonísticos, os conflitos entre indivíduos poderiam não se resolver tão rapidamente e a tensão no grupo poderia atingir níveis difíceis de gerir. A formação de hierarquias de dominância, que resulta destes encontros, ao tornar as interacções sociais menos imprevisíveis, pode ser um meio poderoso de controlo da agressividade.

Os primatas possuem mecanismos para resolver conflitos, reconciliando-se, ou simplesmente diminuindo a tensão através de contacto físico ocasional como parece acontecer no grupo de macacos-uivadores estudado. A elevada frequência de interacções amigáveis no grupo de Agaltepec pode reflectir o potencial agonístico do grupo, uma vez que é constituído por um número elevado de machos adultos. Neste sentido, o comportamento afiliativo pode desempenhar um papel muito significativo na manutenção da ordem social deste grupo. 
Este artigo, que agora se conclui, procurou abordar o significado evolutivo e social do conflito em primatas não-humanos, mas muitos aspectos aqui focados também se podem aplicar ao estudo do conflito em primatas humanos. A capacidade para o conflito, assim como para a sua resolução, também está presente na nossa própria sociedade, e segue uma certa dinâmica universal, comum a macacos, pessoas ou mesmo grupos ou nações.

\section{Agradecimentos}

Agradeço aos investigadores e amigos do Instituto de Neuroetologia da Universidade Veracruzana, no México, por me apoiaram durante todo o período de trabalho de campo. Agradeço ainda aos dois revisores anónimos cujas sugestões enriqueceram o presente artigo. Esta pesquisa foi em parte financiada pela FCT (PRAXIS XXI/BM/10703/97).

\section{Referências bibliográficas}

Altmann, J. 1974. Observation study of behaviour: sampling methods. Behaviour, 49 (2-4): 227-267.

Asensio, N. 2003. Análisis del juego social en el mono aullador (Alouatta palliata) bajo diferentes condiciones socioambientales. Dissertação de Doutoramento, Faculdade de Psicologia, Universidad Autonoma de Madrid.

Aureli, F.; de Waal, F. B. M. (eds.) 2000. Natural conflict resolution. London, University of California Press.

Bernstein, I. S. 1981. Dominance: the baby and the bathwater. The Behavioral and Brain Sciences, 4(3): 419-457.

Bernstein, I. S.; Ehardt, C. 1986. The influence of kinship and socialization on aggressive behaviour in rhesus monkeys (Macaca mulatta). Animal Behaviour, 34(3): 739-747.

Boyd, R.; Silk, J. B. 1983. A method for assigning cardinal dominance ranks. Animal Behaviour, 31(1): 45-58.

Carpenter, C. R. 1965. The howlers of Barro Colorado Island. In: Devore, I. (ed.) Primate behaviour. New York, Holt, Rinehart \& Winston: 250-291.

Casanova, C. 1996. Sobre o comportamento e a organização social de um grupo de chimpanzés (Pan troglodytes) em cativeiro. Lisboa, Instituto Superior de Ciências Sociais e Políticas. 
Clarke, M. R. 1981. Aspects of male behavior in mantled howlers (Alouatta palliata Grey) in Costa Rica. American Journal of Physical Anthropology, 54: 209.

Clarke, M. R. 1984. A comparison of behavior of male and female infant howling monkeys in a free-ranging group in Costa Rica. American Journal of Physical Anthropology, 6: 401.

Colmenares, F.; Hofer, H.; East, M. L. 2000. Greeting ceremonies in baboons and hyenas. In: Aureli, F.; de Waal, F. B. M. (eds.) Natural conflict resolution. London, University of California Press: 94-96.

Cords, M.; Aureli, F. 2000. Reconciliation and relationship qualities. In: Aureli, F.; de Waal, F. B. M. (eds.) Natural conflict resolution. London, University of California Press: 177-198.

Cowlishaw, G.; Dunbar, R. I. M. 1991. Dominance rank and mating success in male primates. Animal Behaviour, 41(6): 1045-1056.

Crockett, C.; Eisenberg, J. 1987. Howlers: variations in group size and demography. In: Smuts, B.; Cheney, D.; Seyfarth, R.; Wrangham, R.; Struhsaker, T. (eds.) Primate societies. Chicago, University of Chicago Press: 54-68.

Darwin, C. 1859. On the origin of species by means of natural selection. London, Murray.

de Vries, H.; Stevens, J. M. G.; Vervaecke, H. 2006. Measuring and testing the steepness of dominance hierarchies. Animal Behaviour, 71(3): 585-592.

de Waal, F. B. M. 1982. Chimpanzees politics: power and sex among apes. New York, Harper and Row.

de Waal, F. B. M. 1987. Dynamics of social relationships. In: Smuts, B.; Cheney, D.; Seyfarth, R.; Wrangham, R.; Struhsaker, T. (eds.) Primate societies. Chicago, University of Chicago Press: 421-429.

de Waal, F. B. M. 1989a. Peacemaking among primates. Harvard: Harvard University Press.

de Waal, F. B. M. 1989b. Dominance 'style' and primate social organization. In: Standen, V.; Foley, R. A. (eds.) Comparative socioecology: the behavioural ecology of humans and other mammals. Oxford, Blackwell: 243-263.

de Waal, F. B. M. 1996. Conflict as negotiation. In: McGrew, W. C; Marchant, L. F.; Nishida, T. (eds.) Great ape societies. Cambridge, Cambridge University Press: $159-172$.

de Waal, F. B. M. 2000. The first kiss: foundations of conflict resolutions research in animals. In: Aureli, F.; de Waal, F. B. M. (eds.) Natural conflict resolution. London, University of California Press: 15-33. 
de Waal, F. B. M.; van Roosmalen, A. 1979. Reconciliation and consolation among chimpanzees. Behavioral Ecology and Sociobiology, 5(1): 55-66.

Dobzhanski, T. 1973. Nothing in biology makes sense except in the light of evolution. American Biology Teacher, 35(3): 125-129.

Fedigan, L. 1992. Primate paradigm: sex roles and social bonds. Chicago, Universtity of Chicago Press.

Fontaine, R. P. 1994. Play as physical flexibility training in five ceboid primates. Journal of Comparative Psychology, 108(3): 203-212.

Garcia, S. 2001. Macacos uivadores: análise do seu comportamento e organização social. Lisboa, Instituto Superior de Ciências Sociais e Políticas.

Harcourt, A. H.; Harvey, P. H.; Larson, S. G.; Shorts, R. V. 1981. Testis weight, body weight and breeding systems in primates. Nature, 293(5827): 55-57.

Harcourt, A.; Purvis, A.; Liles, L. 1995. Sperm competition: mating system, not breeding season, affects testes size of primates. Functional Ecology, 9(3): 468-476.

Isbell, L. A. 1991. Contest and scramble competition: patterns of female aggression and ranging behavior among primates. Behavioral Ecology, 2(2): 143-155.

Isbell, L. A.; Young, T. P. 2002. Ecological models of female social relationships in primates: similarities, disparities, and some directions for future clarity. Behaviour, 139(2-3): 177-202.

Janson, C. H. 2000. Primate socio-ecology: the end of a Golden Age. Evolutionary Anthropology, 9(2): 73-86.

Janson, C. H.; van Schaik, C. P. 2000. The behavioral ecology of infanticide. In: van Schaik, C. P.; Janson, C. H. (eds.) Infanticide by males and its implications. Cambridge, Cambridge University Press: 469-494.

Jones, C. B. 1985. Reproductive patterns in mantled howler monkeys: estrus, mate choice and copulations. Primates, 26(2): 130-142.

Kappeler, P. M.; van Schaik, C. P. 2002. Evolution of primate social systems. International Journal of Primatology, 23(4): 707-740.

Koenig, A.; Beise, J.; Chalise, M. K.; Ganzhorn, J. U. 1998. When females should contest for food - testing hypotheses about resource density, distribution, size, and quality with hanuman langurs (Presbytis entellus). Behavioral Ecology and Sociobiology, 42(4): 225-237.

Kutsukake, N.; Castles, D. L. 2001. Reconciliation and variation in post-conflict stress in Japanese macaques (Macaca fuscata fuscata): testing the integrated hypothesis. Animal Cognition, 4(3): 259-268. 
Lee, P. C. 1983. Context-specific unpredictability in dominance interactions. In: Hinde, R. A. (ed.) Primate social relationship: an integrated approach. Oxford, Blackwell Scientific Publications: 35-44.

Lee, P. C. 1994. Social structure and evolution. In: Slater, P. J. B.; Halliday, T. R. (eds.) Behaviour and evolution. Cambridge, Cambridge University Press: 266-303.

Lorenz, K. 1992. A agressão: uma história natural do mal. Lisboa, Relógio de Água Editores.

Mason, W. A. 1993. The nature of social conflict. In: Mason, W. A.; Mendoza, S. P. (ed.) Primate social conflict. Albany, State University of New York Press: 13-47.

Matsumura, S.; Okamoto, K. 2000. Conflict, social costs, and game theory. In: Aureli, F.; de Waal, F. B. M. (eds.) Natural conflict resolution. London, University of California Press: 79-81.

Maynard Smith, J. 1982. Evolution and the theory of games. Cambridge, Cambridge University Press.

Maynard Smith, J. 1993. Did Darwin get it right? Essays on games, sex and evolution. London, Penguin Books.

Maynard Smith, J.; Parker, G. A. 1976. The logic of asymmetric contests. Animal Behaviour, 24(1): 159-175.

Maynard Smith, J.; Price, G. R. 1973. The logic of animal conflict. Nature, 246(5427): 15-18.

Milton, K. 1980. The foraging strategy of howler monkeys: a study in primate economics. New York: Columbia University Press.

Pellis, S. M.; Pellis, V. C. 1996. On knowing it's only play: the role of play signals in play fighting. Aggression and Violent Behavior, 1(3): 249-268.

Preuschoft, S.; van Schaik, C. P. 2000. Dominance and communication: conflict management in various social settings. In: Aureli, F.; de Waal, F. B. M. (eds.) Natural conflict resolution. London, University of California Press: 77-105.

Ricard, A. 1970. A comparative study of the activity patterns and behaviour of Alouatta villosa and Ateles geoffroyi. Folia Primatologica, 12(4): 241-263.

Roberts, G. 2005. Cooperation through interdependence. Animal Behaviour, 70(4): 901-908.

Roberts, G.; Sherratt, T. N. 1998. Development of cooperative relationships through increasing investment. Nature, 394(6689): 175-179.

Rowell, T. E. 1966. Hierarchy in the organization of a captive baboon group. Animal Behaviour, 14(4): 430-443. 
Seyfarth, R. M. 1981. Do monkeys rank each other? The Behavioral and Brain Sciences, 4(3): 447-448.

Silk, J. B. 1996. Why do primates reconcile? Evolutionary Anthropology, 5(2): 39-42.

Silk, J. B. 1997. The function of peaceful post-conflict contact among primates. Primates, 38(3): 265-279.

Silk, J. B. 2000. The function of peaceful post-conflict interactions: an alternate view. In: Aureli, F.; de Waal, F. B. M. (eds.) Natural conflict resolution. London, University of California Press: 179-181.

Silk, J. B.; Cheney, D. L.; Seyfarth, R. M. 1996. The form and function of postconflict between female baboons. Animal Behaviour, 52(2): 259-268.

Slater, P. J. 1986. Individual differences and dominance hierarchies. Animal Behaviour, 34(4): 1264-1265.

Sousa, C.; Casanova, C. 2005/2006. Are great apes aggressive? A cross-species comparison. Antropologia Portuguesa, 22-23: 71-118.

Strier, K. B. 1992. Causes and consequences of nonaggression in the woolly spider monkey, or muriqui (Brachyteles arachnoides). In: Silverberg, J.; Gray, J. P. (eds.) Aggression and peacefulness in humans and other primates. New York, Oxford University Press: 100-116.

Sussman, R.W.; Garber, P. A.; Cheverud, J. M. 2005. Importance of cooperation and affiliation in the evolution of primate sociality. American Journal of Physical Anthropology, 128(1): 84-97.

Trivers, R. L. 1972. Parental investment and sexual selection. In: Campbell, B. G. (ed.) Sexual selection and the descent of man. Chicago, Aldine: 136-179.

van Hooff, J. A. R. M. 1992. Competition for progeny: the socioecology of primate mating systems. In: Bezemer, W. (ed.) Sex Matters. Proceeding of the $\mathrm{X}^{\text {th }}$ World Congress of Sexology, Amesterdam, 18-22 de Junho, 1991. Elsevier Science Publishers: 93-96.

van Hooff, J. A. R. M. 2001. Conflict, reconciliation and negotiation in non-human primates: the value of long-term relationships. In: Noë, R.; van Hooff, J. A. R. A. M.; Hammerstein, P. (eds.) Economics in nature: social dilemmas, mate choice and biological markers. Cambridge, Cambridge University Press: 67-90.

van Hooff, J. A. R. M.; van Schaik, C. P. 1992. Cooperation in competition: the ecology of primate bonds. In: Harcourt, A. H.; de Waal, F. B. M. (eds.) Coalitions and alliances in humans and other animals. Oxford, Oxford University Press: 357-389.

van Schaik, C. P. 1983. Why are diurnal primates living in groups? Behaviour, 87(1-2): 120-144. 
van Schaik, C. P. 1996. Social evolution in primates: the role of ecological factors and male behaviour. Proceedings of the British Academy, 88: 9-31.

van Schaik, C. P. 2000. Social counterstrategies against infanticide by males in primates and other mammals. In: Kappeler, P. M. (ed.) Primate males: causes and consequences of variation in group composition. Cambridge, Cambridge University Press: 34-54.

Walters, J. R.; Seyfarth, R. M. 1987. Conflict and cooperation. In: Smuts, B.; Cheney, D.; Seyfarth, R.; Wrangham, R.; Struhsaker, T. (eds.) Primate societies. Chicago, University of Chicago Press: 306-317.

Wilson, E. 0. 1975. Sociobiology: the new synthesis. Harvard, Harvard University Press.

Wrangham, R. 1979. On the evolution of ape social systems. Social Science Informations, 18(3): 335-368.

Yarn, D. H. 2000. Law, love, and reconciliation: searching for natural conflict resolution in Homo sapiens. In: Aureli, F.; de Waal, F. B. M. (eds.) Natural conflict resolution. London, University of California Press: 54-70.

Zucker, E.L; Clarke, M. R. 1998. Agonistic and affiliative relationships of adult female howlers (Alouatta palliata) in Costa Rica over a 4-year period. International Journal of Primatology, 19(3): 433-449.

\section{ANEXO}

\section{Caracterização do grupo e local de estudo}

Em 1988, uma equipa do Instituto de Neuroetologia (Universidade Veracruzana), introduziu na Ilha de Agaltepec dois grupos de macacos-uivadores-de-manto com cinco elementos cada. E, na data em que se iniciou o trabalho de campo, em Dezembro de 1996, a ilha já era ocupada por mais de 50 indivíduos.

Neste estudo optou-se por estudar apenas os doze machos adultos perfeitamente integrados no grupo. Os machos quando atingem a puberdade passam a viver de forma marginal ao grupo, ou seja, vivem na periferia e interagem muito esporadicamente com outros elementos do grupo (principalmente fêmeas). Em habitat natural, estes machos iriam viver para outra unidade social, mas neste caso, como não conseguem abandonar a ilha, voltam novamente para o grupo decorridos alguns meses. 
A Ilha de Agaltepec possui uma área total de 8,3 hectares e situa-se num lago pertencente ao município de Catemaco do Estado de Veracruz, México. A ilha é constituída essencialmente por vegetação secundária e rípicola e fornece toda a alimentação necessária aos macacos-uivadores. Desde que os primatas foram introduzidos na ilha nunca mais foram manipulados, nem alimentados por humanos.

\section{Metodologia empregue}

Antes de se iniciar a recolha de dados, realizou-se um período de observações preliminares de 272 horas. Neste período, aprendeu-se a conhecer as 'veredas' da ilha, a identificar os objectos de estudo, definiram-se as categorias comportamentais que iriam ser observadas e desenhou-se todo o projecto de pesquisa. O processo de recolha de dados durou 840 horas e utilizou-se a amostragem focal, registando-se todos os eventos sociais que envolvessem o nosso animal focal quer como emissor quer como receptor (Altmann, 1974). Diariamente, o período de recolha de dados iniciava-se às 7 horas da manhã e terminava às 17 horas da tarde. Durante este período realizávamos um ou dois focais por dia de 5/horas cada. A ordem de selecção dos animais foi estabelecida aleatoriamente no início do estudo. $\mathrm{O}$ trabalho de campo teve a duração total e ininterrupta de seis meses.

Artigo recebido a 22 de Setembro de 2009 e aceite a 6 de Agosto de 2010. 